\title{
A randomized pilot study on the effect of niacin on pulmonary arterial pressure
}

\author{
Martin J. McNamara, Jason J. Sayanlar, Daniel J. Dooley, Monvadi B. Srichai and Allen J. Taylor
}

\begin{abstract}
Background: Niacin induces the release of vasodilating prostaglandins, for which receptors are present within the pulmonary arterial circulation. We hypothesized that immediate-release niacin would reduce right ventricular systolic pressure in patients with pulmonary hypertension in a randomized, double-blinded, single-dose provocation study.
\end{abstract}

Methods: We recruited inpatient subjects with a Doppler echocardiogram showing a peak tricuspid regurgitation (TR) jet velocity of $2.7 \mathrm{~m} / \mathrm{s}$ or greater, and who were free of known pulmonary vascular disease. Subjects were randomized in a 1:2:2 ratio to receive a single dose of either placebo, niacin $100 \mathrm{mg}$ or niacin $500 \mathrm{mg}$, respectively. TR jet velocities were measured immediately before, and 1 hour post dose, corresponding to peak niacin absorption and prostaglandin release. The primary endpoint was the change in mean TR jet velocity measured over ten successive cardiac cycles.

Results: The baseline mean estimated right ventricular systolic pressure (RVSP) for all 49 subjects ( 25 male) was $51.9 \pm$ $12.1 \mathrm{~mm} \mathrm{Hg}$. The primary endpoint of mean change in TR jet velocity was $0.016 \pm 0.065 \mathrm{~m} / \mathrm{s}$ in the placebo group, compared to $-0.017 \pm 0.065 \mathrm{~m} / \mathrm{s}$ with niacin $100 \mathrm{mg}$, and $-0.063 \pm 0.038 \mathrm{~m} / \mathrm{s}$ with niacin $500 \mathrm{mg}(P=0.63)$. The change in maximum estimated RVSP across the three drug groups was $0.2 \pm 1.6 \mathrm{~mm} \mathrm{Hg},-1.3 \pm 1.8 \mathrm{~mm} \mathrm{Hg}$ and $-2.2 \pm$ $1.2 \mathrm{~mm} \mathrm{Hg}(P=0.62)$. In exploratory pairwise analysis in the high-dose niacin group (500 $\mathrm{mg}$ ), the reduction in mean RVSP was from $50.9 \pm 9.4 \mathrm{~mm} \mathrm{Hg}$ to $48.7 \pm 10.0 \mathrm{~mm} \mathrm{Hg}(P=0.09)$.

Conclusions: A single dose of immediate-release niacin (100 mg or $500 \mathrm{mg}$ ) had no significant effect on RVSP 1 hour post administration. A nonsignificant dose-dependent trend for a modest reduction in RVSP, most notable in the $500 \mathrm{mg}$ group, was noted.

(ISRCTN number 12353191, registered April 23, 2015).

\section{Background}

Pulmonary arterial hypertension (PAH) is a rare but increasingly prevalent disease that is characterized by abnormal proliferation, remodeling, and contraction of endothelial cells and smooth muscle cells within the pulmonary artery in association with increased pulmonary artery systolic pressure [1-3]. All approved treatments used to treat PAH target an observable imbalance of vascular tone through vasoconstricting (thromboxanes) and vasodilating (prostaglandins) mediators $[2,4]$. The potent vasoconstrictor thromboxane $\mathrm{A}_{2}$ is countered by the vasodilating prostacyclin $\left(\mathrm{PGI}_{2}\right)$. In patients with $\mathrm{PAH}$, thromboxane $\mathrm{A}_{2}$ is elevated while prostacyclin is

\footnotetext{
* Correspondence: Allen.Taylor@medstar.net

Cardiology Division, Medstar Heart and Vascular Institute at Medstar Georgetown University Hospital and Medstar Washington Hospital Center, 3800 Reservoir Rd., NW, 5 PHC, Washington, DC, 20007, USA
}

diminished, leading to the high pulmonary pressures and resistance.

Intravenous infusion of prostacyclin was the first drug demonstrated to reduce pulmonary artery systolic pressure and improve survival in patients with PAH [5]. Similarly, other vasodilators shown to be active in the pulmonary arteries include calcium channel blockers, endothelial receptor antagonists, nitric oxide, phosphodiesterase (type 5) inhibitors, and synthetic prostacyclin analogues. However, these treatment options are very costly, difficult to administer, and accompanied by many toxicities and complications $[2,6]$. Niacin induces the release of vasodilating prostaglandins, specifically leading to a several hundredfold increase in the concentration of prostaglandin $\mathrm{D} 2\left(\mathrm{PGD}_{2}\right)$ [7]. Through activation of the prostaglandin $\mathrm{D} 2$ receptor, $\mathrm{PGD}_{2}$ mediates the common side effect of cutaneous flushing seen during oral administration. $\mathrm{PGD}_{2}$ 's G protein-coupled receptor, 
$\mathrm{DP}_{1}$, is also located on vascular muscle cells [8]. Thus, given PAH's vasoconstricting properties and niacin's vasodilating abilities, we hypothesized that administration of immediate-release niacin would reduce pulmonary arterial pressure.

\section{Methods}

We conducted a randomized, placebo-controlled, doubleblinded, single-center pilot study on the effect of niacin on pulmonary artery pressure. The study was ethically approved by the Georgetown University Hospital Institutional Review Board (GUH IRB) on October 5, 2011 (study number 2012-067). Taking part in the study was entirely voluntary and informed consent was obtained from every participant. A CONSORT flow diagram and checklist are provided at the end of the manuscript under the Additional files section (Additional files 1 and 2). Echocardiographic tricuspid regurgitation (TR) jet velocity was used as an accurate noninvasive surrogate of pulmonary artery pressure [9-11]. Participants were recruited by screening inpatient echocardiogram logs at MedStar Georgetown University Hospital (MGUH) for Doppler TR jet velocity greater than 2.7 meters $/$ second $(\mathrm{m} / \mathrm{s})$. Patients excluded from the study include the following: inability to provide written, informed consent, known pulmonary vascular disease, known intolerance to niacin or current treatment with niacin, current treatment with a nonsteroidal anti-inflammatory drug (NSAID), known liver disease (aspartate transaminase/alanine transaminase (AST/ALT) $>3$ times the upper limit of normal), or patients currently on ventilator support or using a bi-level positive airway pressure (BiPAP) device.

\section{Study drug}

This was a single-dose provocation study evaluating niacin (100 mg or $500 \mathrm{mg}$ ) versus placebo, in a 2:2:1 ratio. Niacin was administered in the immediate-release, crystalline form of nicotinic acid. The study drug was provided by a research pharmacy with allocation concealed through administration of niacin within identical capsules that either contained placebo or niacin. The randomization sequence was determined using a random number generator and allocation concealed. Subjects were in the nonfasting state prior to study drug administration, but nothing by mouth (NPO) throughout the study.

\section{Echocardiography}

Doppler echocardiography (Philips IE33, Philips Electronics N.V., Amsterdam, The Netherlands) using a 3.5 $\mathrm{mHz}$ transducer was used to measure TR jet velocity immediately pre/post administration of the study drug. Inferior vena cava (IVC) diameter and collapsibility was assessed for estimation of right atrial pressure. After baseline measurements were performed, the patient was immediately administered a single dose of the study medication. Sixty minutes later, corresponding to the usual time of maximal niacin absorption and peak niacin-induced cutaneous flushing, a second echocardiogram was done to reassess TR jet velocity and IVC diameter. To eliminate sonographer variability, the same sonographer performed both the pre and post images. Echocardiography was performed with the patient in the supine position. Doppler recordings of TR jet velocity were acquired using apical, lower left parasternal, and subcostal transducer positions. The best view for TR jet velocity was determined in the baseline echocardiogram. This optimal view of TR jet velocity was used for both the pre and post imaging. The TR jet velocity measurements were determined from the average of ten consecutive cardiac cycles when possible. Otherwise, multiple frames of peaks were captured and the most accurate envelopes were chosen for measurement. TR jet velocities were measured by two independent interpreters unaware of study drug assignment.

\section{Endpoints and statistical analysis}

The primary endpoint was the change in mean TR jet velocity measured in meters/second $(\mathrm{m} / \mathrm{s})$. The secondary endpoint was the change in maximum TR jet velocity. Between-group differences in baseline and endpoint variables were performed using analysis of variance (ANOVA) between the three randomization groups. Dose comparisons were adjusted for multiple endpoint testing using a Bonferroni correction. Right ventricular systolic pressure (RVSP) was estimated via the modified Bernoulli equation. A $P$ value of $<0.05$ was considered statistically significant. Prespecified endpoints were examined using two-tailed hypothesis testing. Exploratory endpoints were examined using one-tailed testing. Statistics were performed using SPSS (version 16.0; SPSS Inc., Chicago, IL, USA).

\section{Results}

A total of 126 patients were approached for consent between June 2013 and April 2014. A total of 50 patients were included in the study. One patient was later excluded from analysis due to a discrepancy on the qualifying echocardiogram. Ten patients were randomized to receive placebo, 19 patients received $100 \mathrm{mg}$ of niacin, and 20 patients received $500 \mathrm{mg}$ of niacin. All enrolled patients completed the study. Baseline characteristics of each group are described in Table 1 . The mean age was $68 \pm 16$, and 25 were men (51 \%). None had known pulmonary vascular disease. Six patients $(12.2 \%)$ had a history of chronic obstructive pulmonary disease. Baseline TR jet velocity was $2.97 \pm 0.38 \mathrm{~m} / \mathrm{s}$, and mean estimated pulmonary artery systolic pressure was $45.9 \pm 9.5 \mathrm{~mm} \mathrm{Hg}$. There were no significant differences in baseline variables between study groups. 
Table 1 Baseline characteristics in patients assigned to placebo, niacin 100 mg, and niacin 500 mg

\begin{tabular}{llll}
\hline & $\begin{array}{l}\text { Placebo } \\
(n=10)\end{array}$ & $\begin{array}{l}\text { Niacin 100 mg } \\
(n=19)\end{array}$ & $\begin{array}{l}\text { Niacin } 500 \mathrm{mg} \\
(n=20)\end{array}$ \\
Age (years) & $69 \pm 18.9$ & $69 \pm 15.5$ & $67 \pm 16.6$ \\
\hline Male (N, \%) & $4(40)$ & $12(63)$ & $9(45)$ \\
Hypertension (N, \%) & $6(60)$ & $12(63)$ & $16(80)$ \\
Diabetes mellitus (N, \%) & $3(30)$ & $5(26)$ & $4(20)$ \\
Hyperlipidemia (N, \%) & $1(10)$ & $3(16)$ & $4(20)$ \\
COPD (N, \%) & $1(10)$ & $3(16)$ & $2(10)$ \\
Smoker (N, \%) & $2(20)$ & $5(26)$ & $9(45)$ \\
Left ventricular ejection & $56 \pm 11.7 \%$ & $51 \pm 13.3 \%$ & $56 \pm 5.8 \%$ \\
fraction & & & \\
\hline
\end{tabular}

COPD chronic obstructive pulmonary disease

The baseline mean estimated RVSP for all 49 subjects (25 male) was $51.9 \pm 12.1 \mathrm{~m} / \mathrm{s}$. The primary endpoint of mean change in TR jet velocity was $0.016 \pm 0.065 \mathrm{~m} / \mathrm{s}$ in the placebo group, compared to $-0.017 \pm 0.065 \mathrm{~m} / \mathrm{s}$ with niacin $100 \mathrm{mg}$, and $-0.063 \pm 0.038 \mathrm{~m} / \mathrm{s}$ with niacin $500 \mathrm{mg}(P=0.63)$. The change in maximum estimated RVSP across the three drug groups was $0.2 \pm 1.6 \mathrm{~mm}$ $\mathrm{Hg},-1.3 \pm 1.8 \mathrm{~mm} \mathrm{Hg}$ and $-2.2 \pm 1.2 \mathrm{~mm} \mathrm{Hg}(P=$ $0.62)$. In exploratory pairwise analysis in the high-dose niacin group (500 $\mathrm{mg}$ ), the reduction in mean RVSP was from $50.9 \pm 9.4 \mathrm{~mm} \mathrm{Hg}$ to $48.7 \pm 10.0 \mathrm{~mm} \mathrm{Hg}(P=0.09)$. Exploratory pairwise analysis in the other two groups yielded nonsignificant $P$ values. There were no differences observed within strata of baseline RVSP (above or below median RVSP) or for age (Fig. 1).

\section{Discussion}

We hypothesized that niacin-mediated prostaglandin release might lead to measurable acute effects on right ventricular systolic pressure in patients with pulmonary hypertension. In this pilot study, we have shown that major changes in RVSP were not observed after singledose provocation with $100 \mathrm{mg}$ or $500 \mathrm{mg}$ of niacin. However, with a dose-response difference, our data are consistent with a possible small reduction in RVSP at the $500 \mathrm{mg}$ dose. These data provide insights for future studies on the topic, in particular dosing, effects of dosing at 1 hour, and data for sample size determinations.

Long known is niacin's principle side effect of vasodilatory flushing, exhibited after oral ingestion of large doses or immediate-release niacin. The physiological mechanism of flushing relates to an abnormally large concentration of prostaglandins released upon niacin absorption, predominantly $\mathrm{PGD}_{2}$ [7]. Ingested niacin binds to $G$ protein-coupled receptor 109A (GPR109A), triggering a signal cascade leading to $\mathrm{PGD}_{2}$ formation and release [12]. Subsequent vasodilation only occurs after $\mathrm{PGD}_{2}$ binds to its receptor $\mathrm{DP}_{1}$, located on vascular muscle cells $[8,13]$. This knowledge led to our hypothesis that pulmonary artery vasodilation may be a physiological correlate of niacin-induced prostaglandin release.

Niacin has not previously been investigated for its effects on pulmonary artery pressure. Indeed, new simple and low-cost treatments for PAH are needed. Low levels of vasodilating prostaglandins and high levels of vasoconstricting thromboxanes result in the high pulmonary pressures and resistance evident in patients with $\mathrm{PAH}$ $[2,4]$. Long-term, intravenous administration of prostacyclin $\left(\mathrm{PGI}_{2}\right)$ has seen the most success in treating this imbalance, providing symptomatic alleviation, hemodynamic improvement, and prolonged survival in patients $[5,6]$. It has also been shown to significantly reduce echocardiographic measurements of maximum TR jet velocity after 12 weeks of therapy [14]. However, complications are common and new treatment options using synthetic prostacyclin analogues and other prostaglandins are continuously being explored. A particular limitation of such treatments is their expense.

Several opportunities exist for applying these results to future studies. First, without appropriate animal models or prior experience to guide us, we selected doses of $100 \mathrm{mg}$ and $500 \mathrm{mg}$ of niacin based largely on the maximal initial doses of immediate-release niacin that are tolerable. Based upon pharmacokinetic bioavailability, we estimated that 1 hour post administration would be the time of exposure to maximal $\mathrm{PGD}_{2}$ levels correlating to the typical period of cutaneous flushing. This study explored niacin's (putatively via $\mathrm{PGD}_{2}$ ) ability to quantitatively reduce pulmonary arterial pressure assessed using TR jet velocity. Although we found no overall effect, several potential opportunities for future research emerged. First, our data suggests a positive trend with larger reductions of pulmonary arterial pressure at the highest dose $(500 \mathrm{mg})$ of niacin. Second, our data are compatible with a small reduction in RVSP at the $500 \mathrm{mg}$ dose, although we caution that this is a subgroup endpoint and found within exploratory statistical methods that require further hypothesis generation and testing. Our study supports the feasibility and safety of administration of niacin as a pulmonary vasodilator among patients with overall mild to moderate pulmonary hypertension. Given the indirect nature of assessment of RVSP using TR jet velocity, future studies should utilize more direct techniques such as pulmonary artery catheterization that, although invasive, would be more definitive and aid in the determination of the time course of effect. For example, intravenous prostacyclin in acute administration results in little change in pulmonary artery systolic pressure due to an offsetting effect of increased cardiac output in the setting of pulmonary artery vasodilation [14]. As niacin may stimulate a number of offsetting hemodynamic variables such as 


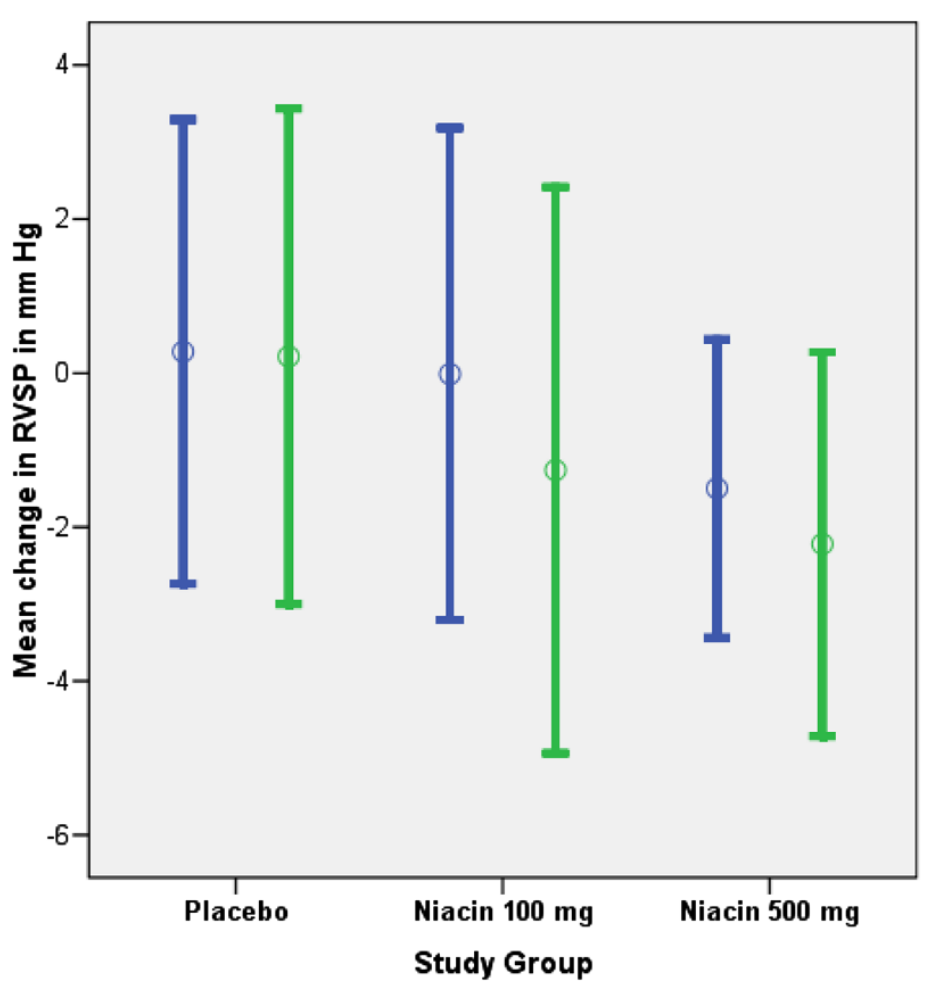

RVSP mean change

RVSP max change

Fig. 1 Mean and maximum change in RVSP in $\mathrm{mm} \mathrm{Hg}$ in all study groups. Mean change in estimated right ventricular systolic pressure (RVSP) in $\mathrm{mm} \mathrm{Hg}$ for placebo, niacin $100 \mathrm{mg}$, and niacin $500 \mathrm{mg}$ measured 1 hour after medication administration. Data displayed are for the changes observed in average RVSP (b/ue), and in maximum RVSP (green) observed in up to ten consecutive Doppler measurements

increased cardiac output in a setting of reduced pulmonary vascular resistance yielding no net effect on RVSP, the hypothesis that niacin induces pulmonary artery vasodilation may not be inconsistent with our initial findings.

\section{Limitations}

We utilized TR jet velocity as a surrogate to pulmonary pressure given its noninvasive nature and the pilot study approach. Although accurate, the pressures derived are dependent on a number of assumptions and technical optimization. Although we attempted to eliminate interest variability through consistency in the sonographer and insonation views, a more direct approach utilizing pulmonary artery catheterization would be advised for more definitive evaluation. There are many different etiologies underlying PAH. Additionally, not all forms of PAH will respond equally to vasodilators. This introduces the possibility of a heterogeneous study population. We selected a niacin dose for this study based upon tolerance for initial dosing of the drug. If potential favorable effects on pulmonary artery pressure are shown through future studies, dose optimization during titration and sustained administration would be necessary.
Our study was designed to detect a small change in TR jet velocity, although the standard deviation was larger than anticipated. Our data should aid future investigators in sample size determinations. Lastly, we empirically elected to assess the change in TR jet velocity after 60 minutes, based upon the time course of clinical flushing caused by increased circulating levels of $\mathrm{PGD}_{2}$. However, absorption rates between patients may vary, and indeed patients differed in the time when maximum flushing occurred, most prior to the second echocardiogram and a few after.

\section{Conclusions}

Niacin, via stimulation of $\mathrm{PGD}_{2}$ release, may favorably reduce pulmonary artery pressure in patients with mild to moderate pulmonary artery hypertension. However, this pilot study did not meet its primary and secondary endpoints of change in mean and maximum TR jet velocity, while demonstrating a trend for dose response and possible reduction of RVSP at the $500 \mathrm{mg}$ dose. Future studies utilizing direct measurements of pulmonary artery pressure and repeat niacin dosing are warranted. 


\section{Additional files}

\section{Additional file 1: CONSORT flow diagram for the Niacin Study.} (DOCX $32 \mathrm{~kb}$ )

Additional file 2: CONSORT 2010 Checklist for the Niacin Study. (DOCX $38 \mathrm{~kb})$

\section{Abbreviations}

ANOVA: analysis of variance; ALT: alanine transaminase; AST: aspartate transaminase; Bi-PAP: bi-level positive airway pressure; GPR109A: G-protein coupled receptor 109A; IVC: inferior vena cava; MGUH: MedStar Georgetown University Hospital; m/s: meters/second; NPO: nothing by mouth; NSAID: nonsteroidal anti-inflammatory drug; PAH: pulmonary arterial hypertension; $\mathrm{PGD}_{2}$ : prostaglandin $\mathrm{D}_{2} ; \mathrm{PGI}_{2}$ : prostacyclin or prostaglandin $\mathrm{I}_{2}$; RVSP: right ventricular systolic pressure; TR: tricuspid regurgitation.

\section{Competing interests}

The authors declare that they have no competing interests.

\section{Authors' contributions}

JS and AT envisioned the study, coming up with the design and rational. MM carried out the screening, recruiting, and enrollment of all research subjects, as well as drafting the original manuscript. DD helped with the recruiting phase of the study and the acquisition of patient demographics. MM and BS performed all echocardiographic measurements. AT performed the statistical analysis. All authors interpreted the final findings and participated in the drafting and approval of the final manuscript.

\section{Acknowledgements}

We thank all MedStar Georgetown University Hospital echocardiographic technicians who performed all echocardiograms of enrolled subjects. Also, we thank the Georgetown research pharmacy for the preparation and blinding of the study drugs. Finally, we thank the Folger Grant for Cardiovascular Prevention for funding this research study.

\section{Received: 5 March 2015 Accepted: 15 October 2015}

Published online: 21 November 2015

\section{References}

1. McLaughlin W, McGoon MD. Pulmonary arterial hypertension. Circulation. 2006;114:1417-31.

2. Montani D, Chaumais MC, Guignabert C, Gunther S, Girerd B, Jais X, et al Targeted therapies in pulmonary arterial hypertension. Pharmacol Ther. 2014;141:172-91.

3. Voelkel NF, Quaife RA, Leinwand LA, Barst RJ, McGoon MD, Meldrum DR, et al. Right ventricular function and failure: report of a National Heart, Lung, and Blood Institute working group on cellular and molecular mechanisms of right heart failure. Circulation. 2006;114:1883-91.

4. Christman BW, McPherson CD, Newman JH, King GA, Bernard GR, Groves $\mathrm{BM}$, et al. An imbalance between the excretion of thromboxane and prostacyclin metabolites in pulmonary hypertension. N Engl J Med. 1992:327:70-5

5. Barst RJ, Rubin L, Long WA, McGoon MD, Rich S, Badesch DB, et al. A comparison of continuous intravenous epoprostenol (prostacyclin) with conventional therapy for primary pulmonary hypertension. N Engl J Med. 1996:334:296-301.

6. Olschewski H, Rose F, Schermuly R, Ghofrani HA, Enke B, Olschewski A, et al. Prostacyclin and its analogues in the treatment of pulmonary hypertension. Pharmacol Ther. 2004;102:139-53.

7. Morrow JD, Parsons 3rd WG, Roberts 2 nd LJ. Release of markedly increased quantities of prostaglandin D2 in vivo in humans following the administration of nicotinic acid. Prostaglandins. 1989;38:263-74.

8. Cheng K, Wu TJ, Wu KK, Sturino C, Metters K, Gottesdiener K, et al. Antagonism of the prostaglandin D2 receptor 1 suppresses nicotinic acid-induced vasodilation in mice and humans. Proc Natl Acad Sci U S A. 2006;103:6682-7.

9. Berger M, Haimowitz A, Van TA, Berdoff RL, Goldberg E. Quantitative assessment of pulmonary hypertension in patients with tricuspid regurgitation using continuous wave Doppler ultrasound. J Am Coll Cardiol. 1985;6:359-65.
10. Currie PJ, Seward JB, Chan KL, Fyfe DA, Hagler DJ, Mair DD, et al Continuous wave Doppler determination of right ventricular pressure: a simultaneous Doppler-catheterization study in 127 patients. J Am Coll Cardiol. 1985;6:750-6.

11. McQuillan BM, Picard MH, Leavitt M, Weyman AE. Clinical correlates and reference intervals for pulmonary artery systolic pressure among echocardiographically normal subjects. Circulation. 2001;104:2797-802.

12. Benyo Z, Gille A, Kero J, Csiky M, Suchankova MC, Nusing RM, et al. GPR109A (PUMA-G/HM74A) mediates nicotinic acid-induced flushing. J Clin Invest. 2005;115:3634-40

13. Benyo Z, Gille A, Bennett CL, Clausen BE, Offermanns S. Nicotinic acidinduced flushing is mediated by activation of epidermal langerhans cells. Mol Pharmacol. 2006:70:1844-9.

14. Nootens M, Schrader B, Kaufmann E, Vestal R, Long W, Rich S. Comparative acute effects of adenosine and prostacyclin in primary pulmonary hypertension. Chest. 1995;107:54-7.

\section{Submit your next manuscript to BioMed Central and take full advantage of:}

- Convenient online submission

- Thorough peer review

- No space constraints or color figure charges

- Immediate publication on acceptance

- Inclusion in PubMed, CAS, Scopus and Google Scholar

- Research which is freely available for redistribution

Submit your manuscript at www.biomedcentral.com/submit 